\title{
DISTINCIONES BÁSICAS Y ESPECIFICIDAD DE LA CONSULTORÍA FILOSÓFICA EN RELACIÓN A LAS PSICOTERAPIAS
}

\author{
BASIC DISTINCTIONS AND SPECIFICITY OF THE \\ PHILOSOPHICAL CONSULTANCY IN RELATION TO \\ PSYCHOTHERAPIES
}

\author{
OSCAR VALENCIA MAGALLÓN \\ Instituto de Filosofía de Guadalajara \\ oscarorej@yahoo.com
}

RECIBIDO: 4 DE OCTUBRE DE 2018

ACEPTADO: 5 DE NOVIEMBRE DE 2018

Resumen: El siguiente texto define de manera general la consultoría filosófica como una forma peculiar de práctica filosófica que se encuentra, en cuanto a su formato y el ideario actual, relacionada a las psicoterapias, lo cual genera inquietudes acerca de qué le es propio y qué la distingue de estos abordajes, sean éstos de orientación psicosocial o clínica. Durante el artículo, enmarcaremos a la consultoría filosófica dentro del modelo de prácticas filosóficas para posteriormente definir sus elementos constitutivos según diversos autores, así como lo peculiar y lo distinto en comparación con otros abordajes interpersonales no filosóficos.

Palabras clave: práctica filosófica, consultoría filosóficas, psicoterapias, terapia, distinciones.

\begin{abstract}
The following text defines in a general way the philosophical consultancy as a peculiar form of philosophical practice that is, in terms of its format and the current ideology, related to psychotherapies, which generates concerns about what is its own and what distinguishes it of these approaches, whether they are psychosocial or clinical. During the article, we will frame the philosophical consultancy within the model of philosophical practices to later define its constituent elements according to different authors, as well as the peculiar and the different compared to other non-philosophical interpersonal approaches
\end{abstract}


Keywords: philosophical practice, philosophical consulting, psychotherapies, therapy, distinctions

\section{Práctica filosófica y consultoría filosófica}

La filosofía como saber orientado a los problemas de la ciencia y de la historia del pensamiento filosófico no representa en definitiva el único modo de entender a la filosofía, aunque sí representan de modo general su tradición. No obstante, debemos comentar que sería impreciso no reconocer una orientación distinta y no academicista-revisionista de la filosofía en su propia historia, pues existe también una amplia tradición que remite a su carácter vital y práctico. Tenemos como ejemplo de lo anterior al estoicismo y epicureísmo de la filosofía helenística ${ }^{1} \mathrm{y}$, contemporáneamente, al existencialismo del siglo $\mathrm{XX}$ donde encontramos una marcada alusión a la filosofía como un modo de afirmar la vida, la voluntad y el ser propio, a distancia de un revisionismo especulativo del mero concepto de vida y una acrítica sujeción de la vida como existencia al saber científico.

Estas orientaciones sobre la relación filosofía y vida han decantado en diversos proyectos filosóficos, siendo uno de ellos la práctica filosófica, que se ha manifestado en el surgimiento de múltiples prácticas alejadas del academicismo de las universidades y los grandes centros oficiales de la filosofía, dando lugar a experiencias particulares de la filosofía que atienden demandas de carácter existencial, terapéutico, político, estético y espiritual. La práctica filosófica como modalidad de la filosofía busca atender la apremiante voluntad de aplicar la filosofía a la vida que está sucediendo ahora. Dentro de las diversas prácticas que derivan del modelo de la filosofía que comentamos, se desprende la consultoría

${ }^{1}$ Vid., HADOT Pierre, ¿Qué es la filosofía antigua?, FCE, México,1998, págs.11-17. 
filosófica como un ejercicio de aplicación de la filosofía a la experiencia personal, en su dimensión vital e histórica que definiremos más adelante.

\section{Definición de práctica filosófica}

¿Qué es la práctica filosófica? La práctica filosófica es una modalidad del filosofar en donde la Filosofía se concibe como una actividad humana de primer orden, con fines democráticos y éticos que son desarrollados, promovidos y comunicados en todo lugar y para todos escapando del academicismo de los grandes centros de estudio, así como del elitismo intelectual. La filosofía es aquí una actividad de todos y para todos, pero una actividad que representa una herramienta inigualable para la realización humana en el orden ético, cívico y existencial.

Para abonar a una definición más estricta, diremos que en la práctica filosófica se prioriza más al filosofar que a la filosofía, entendida esta última como el producto del filosofar que busca tematizar la realidad de manera discursiva, metódica, rigurosa, fundante y última en relación con las distintas ciencias. El filosofar refiere en su caso a las tareas de quien pone en juego su pensamiento estableciendo preguntas radicales, dando lugar a cuestionar lo discursivo y lo práctico, integrando el análisis y la crítica, bajo el esquema del diálogo y la consideración de que todo sujeto es competente en el filosofar.

Según el diagnóstico de la UNESCO, la práctica filosófica representa una modalidad de la filosofía arraigada en el pragmatismo y en ciertos principios socioculturales de la posmodernidad. $^{2}$ En cuanto al primero, se parte de una

${ }^{2}$ UNESCO, La filosofía, una escuela para la libertad, UNESCO-UAM, México, 2007, págs. 161-177. 
representación lingüística del mundo. El lenguaje como instancia en donde se contiene el ser de las cosas determina el sentido general de las acciones. Según esta concepción, en el lenguaje concebimos nuestro ser como humanos y este mismo es el que define el sentido y dirección de las prácticas que, en última instancia, son las generadoras de mundo. Podemos decir que desde el pragmatismo el lenguaje delimita lo que puede ser representado como acción humana, estableciendo que el mundo es, en primera y última instancia, lo que significamos y configuramos a través de la acción y el sentido como dimensiones lingüísticas.

En cuanto a la posmodernidad, la práctica filosófica reivindica el valor de la individualidad, la pluralidad, el principio dialógico y la libre determinación de las prácticas fundamentadas desde el mundo mismo, a distancia de los metarrelatos suprahumanos $o$ suprahistóricos como la religión, el Estado o principios metafísicos totalizantes y ordenadores del status quo (ideologías). La ausencia de estos metarrelatos explica el lugar preponderante que los individuos dan a su propia palabra como determinación del ser y las acciones. Existe además una transformación de los mecanismos socioeconómicos tradicionales que ha derivado en la necesidad de replantearse nuevos principios, esquemas de creencias y principios de orientación, situación que debe ser tratada eminentemente de manera filosófica. Podemos decir que se da mayor peso al sujeto que está detrás de los discursos que a los discursos en sí mismos, destacando la universalidad de la capacidad humana inherente del filosofar que se urge ahora para dar respuesta a la necesidad profunda de encontrar sentido a la corriente de experiencias, bajo un horizonte ético, democrático, libre, histórico y temporal.

La práctica filosófica parte de una idea de la filosofía que considera que el ser humano, por el hecho de serlo, busca mediante la crítica, comunicación, diálogo y distancia ante lo dado, mejores condiciones para la humanización. Según esta idea, todos somos 
filósofos en alguna medida y vivimos en un tiempo que apremia el cultivo de esta dimensión antropológica de primer orden.

Definida ya la categoría de práctica filosófica en su objeto, finalidades y supuestos teóricos, comentamos que ésta cobija un conjunto de prácticas que atienden intereses y necesidades existenciales, terapéuticas, políticas, culturales e intelectuales. En este sentido, consideramos a la consultoría filosófica como una práctica filosófica particular, centrada en dar respuesta a diversas necesidades metafísicas (existenciales, cognoscitivas religiosas, políticas, entre otras) vividas en la subjetividad generalmente de manera profunda y radical.

\section{Definición de consultoría filosófica}

La consultoría filosófica ha generado una serie de configuraciones teóricas y prácticas que vale la pena abordar en su propio espacio. $\mathrm{Su}$ historia se remite, quizá simbólicamente, al consultorio filosófico inaugurado en Alemania por Gerd B. Achenback en los 80's, quien ofrecía un espacio para la revisión de los conflictos personales, existenciales y de sentido que podían, desde su juicio, ser abordados por la aplicación de principios filosóficos y el análisis de los pensamientos. ${ }^{3}$ Llamaba "huéspedes" a quienes asistían a estos momentos de interacción señalando con esto el carácter del encuentro filosófico como un encuentro libre, alejado de la categoría de patología, que guardaba fines pedagógicos bajo el respeto irrestricto de la propia individualidad, destacando su carácter personal y racional. A partir de este suceso se fueron creando organizaciones que conjuntaban esfuerzos de filósofos que se sentían identificados con la concepción de una filosofía que podría ser aplicada para el tratamiento de inquietudes o conflictos

${ }^{3}$ RAABE, Peter, Philosophical counseling, Praeger, USA, 2001, págs. 3-6 
que se instalaban en la subjetividad y que desde ahí buscaban un abordaje.

¿Qué es una consultoría filosófica?

Existen varios conceptos para referir a esta práctica filosófica. Se conoce como counseling filosófico, como consultoría, como asesoría o como orientación filosófica. Los términos varían según las funciones, alcances y límites que se adjudiquen a este ejercicio, a la variante de la traducción entre el mundo anglo y el mundo hispano y también a las preferencias de los consultores o filósofos prácticos.

\section{Algunos modelos de consultoría filosófica}

Existen diversas definiciones de consultoría filosófica, mencionaremos algunas en cuanto su definición y metodología.

Mónica Cavallé sostiene que la consultoría filosófica es una actividad destinada a transformar la concepción de uno mismo bajo la búsqueda y descubrimiento de la filosofía personal. ${ }^{4}$ Considera que todo verdadero saber transforma y que el conocimiento implica comprensión, pero en el sentido de la modificación del ser personal. Considera como guía de todo proceso del ser a la sabiduría, de la cual comenta: "La sabiduría nos dice que conocer profundamente algo es serlo", ser se realiza en una toma de conciencia o comprensión de algún aspecto de la realidad y, paralelamente, toda comprensión profunda nos transforma. Considera que esto deriva en el "despertar". Propone como metodología la aplicación en conjunto de las

\footnotetext{
${ }^{4}$ Vid., CAVALLÉ, Mónica, La sabiduría recobrada. Filosofía como terapia, Kairós Madrid, 2002

CAVALlÉ, Mónica, La filosofía, maestra de vida, Grupo Santillana Aguilar, Madrid:, 2004

${ }^{5}$ Op. Cit., CAVALLÉ, Mónica. La sabiduría recobrada, pág. 51
} 
siguientes acciones: escucha hermenéutica o comprensiva, reinterpretación o resignificación, descubrimiento de visiones del mundo latentes, mayéutica, elántica o arte de refutar, clarificación de valores y objetivos, análisis de creencias, análisis de conceptos, examinar los argumentos mediante el uso de la lógica, la fundamentación de las opiniones verdaderas, la reelaboración de la nueva cosmovisión, traer ideas filosóficas a las sesiones, aplicación de las tecnologías del yo, procedimiento fenomenológico entre otras.

José Barrientos dirá que la Filosofía Aplicada, término que utiliza para el trabajo individual y los talleres grupales, no implica ningún tipo de trabajo con fines terapéuticos. Esto se debe a varias razones que ofrece. En primer lugar, muchas terapias se han vinculado con trabajos clínicos y con la enfermedad mental, ubicándose en un esquema que no corresponde a la profesión del filósofo. Por otro lado, muchas terapias conducen a un proceso de socialización acrítico, mientras que la filosofía aplicada tiene como uno de sus ejes la crítica de sus propias metodologías y de los fines sociales que constituyen las sociedades. Así, la Filosofía Aplicada llega a criticar muchas terapias por su adhesión sin juicio a parámetros que interesan a instituciones del capitalismo galopante. Por último, el modelo de la Filosofía Aplicada, de acuerdo con Barrientos, tiene en su centro el acto filosófico: su primera definición indica que el objetivo es la mejora del acto de pensamiento, la conceptualización y la clarificación de los términos implicados en el asunto del consultante o grupo. Esta idea no sólo se corresponde con una aproximación discursiva, o lógico-argumental, como señala en sus escritos desde hace más de una década, sino que se amplía desde otros tipos de metodologías filosóficas (hermenéutica, fenomenología, etc...) como se evidencia en su Filosofía Aplicada Experiencial. De acuerdo con ésta última, la Filosofía Aplicada consiste en la materialización de metodologías científicas con fines estrictamente filosóficos (clarificación de la verdad, desarrollo de 
la agudeza intelectiva o sutileza, descubrimiento de verdades transformadoras o evidencias) aunque, como sucede en otras disciplinas, pueda rendir resultados no buscados. Por ello, Barrientos se afilia a los términos de Peter Raabe en la afirmación siguiente: la Filosofía Aplicada no es terapia, aunque pueda tener resultados terapéuticos. ${ }^{6}$

La argentina Roxana Kreimer dirá que el asesoramiento filosófico se define como un abordaje que permite tratar con los problemas existenciales y las falsas creencias a través del buen razonamiento y las herramientas del pensar filosóficos, teniendo como base del diálogo la empatía y la igualdad; el consultante no es enjuiciado sino acompañado en un marco de libertad para el diálogo. Como método propone la aplicación de los siguientes instrumentos filosóficos: Examen de los argumentos del consultante y de sus justificaciones, clarificación y análisis de términos y conceptos, exposición de presupuestos implícitos e implicaciones lógicas, exposición de contradicciones e incoherencias, rastreo de teorías filosóficas, teorías alternativas que pueden ampliar el horizonte de reflexión y biblioterapia. ${ }^{7}$

Peter B. Raabe dirá que la consultoría filosófica ayuda a un individuo a tratar con los problemas o conflictos personales cuando éste, por sí mismo, ha llegado a un callejón sin salida que pudiera ver la luz a partir de la aplicación de principios filosóficos. Propone identificar el proceso de consultoría en cuatro pasos: en primer lugar, la escucha atenta y comprehensiva del cliente, en donde el cliente se familiariza con el modo de trabajo del consultor estableciendo sus preocupaciones. El segundo paso consiste en que el consultor intenta ayudar a su cliente a resolver sus problemas y preocupaciones más inmediatas; aquí el consultante ve al consultor como un experto y hace uso de sus capacidades de razonamiento

\footnotetext{
${ }^{6}$ Comunicación personal, recibida en octubre de 2018.

${ }^{7}$ Vid., KREIMER, Roxana, Artes del buen vivir, Paidós, España, 2005, págs. 722.
} 
para resolver sus propias dificultades. En tercer término, el filósofo se coloca en el papel de maestro para ofrecer alternativas mediante el recurso a la tradición filosófica para desarrollar en el cliente propias habilidades de razonamiento y las disposiciones filosóficas necesarias para producir un movimiento personal de búsqueda y cuestionamiento que pertenezca sin más al cliente y lo convierta en un pensador autónomo. En el último estadio se invita al cliente a trascender la orilla inmediata del problema a resolver para arribar al cuestionamiento de los supuestos y valores incuestionados en su propia visión del mundo y, con ello, alcanzar la sabiduría que permite ver de manera más profunda y amplia aquello que no se había revelado antes. Dejar de ser una máquina automática para correr a ser pensadores autónomos que podamos satisfacer visiones más amplias y adecuadas de la vida buena.

Oscar Brenifier, por su parte, establecerá que la práctica filosófica implica un diálogo deconstructivo ante el encuentro con lo real y con lo otro, es decir, un proceso de deconstrucción que echa abajo lo no racionalizado, argumentado y fundamentado. ${ }^{8}$ El objetivo es que cada participante sea consciente de su peculiar aprehensión del mundo y de sí mismo, delibere sobre las posibilidades de otros esquemas de creencias y se comprometa en un proceso dialéctico que le permita trascender sus propias opiniones. Y aquí es donde se encuentra la esencia de la actividad filosófica: en la trasgresión de la opinión personal y del modo subjetivo de experimentar el mundo para reconciliarnos con lo otro, lo extraño. Brenifier define la práctica filosófica como una actividad constitutiva por sí misma y determinada por tres operaciones: la identificación, la crítica y la conceptualización. ${ }^{9}$ Se busca "que el consultante evalúe las

\footnotetext{
${ }^{8}$ Vid., BRENIFIER, Oscar, “Puede la filosofía convertirse en una práctica?”, Diálogo Filosófico, 68 (2007), 217-228.

${ }^{9}$ Vid., BRENIFIER e MILLON, "Cuaderno 1 de ejercicios de práctica filosófica en la escuela", [Traducción Mercedes $G^{\mathrm{a}}$ Márquez.], CECAPFIN, México, S/A, págs. 3-15
} 
situaciones y salga del alboroto de la acción y del hilo de la narración para captar los elementos esenciales de la consulta filosófica y los puntos de inflexión del diálogo. El sujeto se implica así en un metadiscurso con respecto a las vacilaciones y tanteos de su propio pensamiento. Este momento es crucial, porque es el lugar de la toma de conciencia de este funcionamiento dual de la mente humana (dentro/fuera), intrínsecamente unido a la práctica filosófica, y permite el surgimiento de una perspectiva hacia el infinito que hace que el sujeto acceda a una visión dialéctica de su propio ser y a la autonomía de su pensamiento." 10

En nuestra perspectiva, la consultoría filosófica es una actividad por la cual se sirve al otro a través del pensamiento en su carácter filosófico -un pensar formado y habituado a los problemas, métodos y tradición filosóficos-. Esto se realiza en el rol de un "otro" mediante el diálogo respetuoso y simétrico con la finalidad de tratar conflictos y necesidades de intelección profundas que den cauce intencionado a las necesidades afectivas-existenciales de comprensión de la persona. Se considera posible que, como consecuencia de la labor filosófica, la persona logre experimentar bienestar personal-comunitario bajo un horizonte crítico, reflexivo y solidario.

Para nosotros, la consultoría filosófica representa un modo original y propio de tratar ámbitos de la realidad humana en su relación con el mundo y los otros bajo la consigna de que el pensar nos remite a la posibilidad de humanizarnos, escapando de las representaciones acríticas, no filosóficas que de la vida se hacen, indagando por la comprensión y verdad de los problemas que aparecen ante nosotros, bajo el supuesto de que a mayor verdad y comprensión, mayor integración con lo real, situación que nos impele de facto y a la que estamos dirigidos en la tarea de vivir.

${ }^{10}$ BRENFIER, Filosofar como Sócrates, Diálogo, España, 2011, p. 61 


\section{Distinciones entre la consultoría filosófica y abordajes psicoterapéuticos}

La necesidad de aprender a vivir y saber cómo hacerlo representan una inquietante cuestión. Esta condición, en cuanto su permanencia antropológica, ha sido abordada por distintos agentes culturales y sociales a lo largo del tiempo: la religión, el estado, la psicología, entre otros. En este sentido, podemos decir que vivimos ahora un entorno que intenta dar respuesta a esta necesidad profunda desde una psicologización de la vida. A lo anterior habrá que sumar "la medicalización de la vida" relacionada con la psiquiatría en el afán de ayudar a lograr vidas funcionales, particularmente los casos de sujetos con deficiencias biológicas y ambientales marcadas. Estas dos perspectivas podrían representar las alternativas más comunes hoy en torno a cómo tratar con la vida humana en su dimensión personal e interpersonal para hacerla más funcional y satisfactoria, aunque no agoten la necesidad profunda de aprender y saber vivir enunciadas al inicio del párrafo y que ha sido objeto de la filosofía desde sus orígenes.

En relación con lo anterior, vislumbramos que sacar a la filosofía de su ámbito academicista y actualizar su función ética para dar respuesta a la necesidad profunda de saber vivir, bajo el formato de un acompañamiento personal-existencial, pudiera generar dudas y confusiones en las funciones que se adjudican a los profesionales de la psicoterapia, la psiquiatría y la filosofía. Buscaremos en la medida de lo posible mostrar lo propio de cada abordaje con la finalidad de reflexionar sobre lo esencial de la consultoría filosófica $\mathrm{y}$ focalizar sus alcances ante otros abordajes no filosóficos, recuperando su talante terapéutico presente en su tradición y que se perdió de vista ante el revisionismo de la filosofía, en su definición como erudición bajo una restringida función epistemológica. 
Diferencias entre consultoría filosófica y otros abordajes en cuanto al objeto

Consideramos que el objeto de la consultoría filosófica se puede estructurar en cuatro dimensiones: a) el worldview interpretation o cosmovisión conformadas en la razón por la cultura y la sociedad, b) las operaciones de pensamiento incongruentes, inflexibles o desproporcionadas que implican la intervención de las leyes de la lógica formal e informal, así como las habilidades de pensamiento superior y crítico; c) aquellas que tocan dimensiones humanas centrales que urgen la reflexión filosófica en las crisis existenciales, situaciones límite y crisis cognoscitivas. Por último, d) el conocimiento de sí mismo y la determinación de la vida buena, bajo la condición de un modo de vida filosófico.

Las dimensiones referidas comportan apertura al cultivo y desarrollo de la racionalidad en su vertiente cognoscitiva, ética y reflexiva. Por esta misma condición, son susceptibles de ser clarificadas, reflexionadas, evaluadas y transformadas mediante el ejercicio filosófico de crítica, análisis e interpretación, lo cual explica que su modificación incida directa o indirectamente en pautas de conducta. Lo anterior asume la recuperación que hacen Hadot $^{11}$ y Nussbaum ${ }^{12}$ acerca de la filosofía helenística sobre el contenido racional o argumental de las emociones y las acciones. Además, del cultivo de la racionalidad, apela al cultivo del alma (en los antiguos) o al cuidado de si (en la filosofía posterior). De aquí el que pueda esperarse de la consultoría filosófica no sólo un cambio en las concepciones de la vida o en las habilidades del pensar, sino también una modificación en el propio modo de llevar

\footnotetext{
${ }^{11}$ Vid., HADOT, Pierre, ¿Qué es la filosofía antigua?, FCE, 1998, pp. 11-17.

${ }^{12}$ Vid., NUSSBAUM, Martha, La terapia del deseo, teoría y práctica de la ética helenística, Paidós, Barcelona, 2003, 33-74
} 
la vida $\mathrm{y}$ asumir activamente las crisis existenciales o cognostivas. ${ }^{13}$

A diferencia de lo anterior, la psicología psicodinámica (tomamos al psicoanálisis y humanismo como los ejemplos más representativos) tienen como objeto la mente o el yo del sujeto donde las diversas escuelas de estas corrientes afirman un modelo de funcionamiento tematizado en conceptos como "dinámica", "causalidad" o "leyes de la mente". Es decir, se supone una imagen de la mente o del yo arreglada a fines, dinámicas reguladoras o leyes que se teorizan y explican la expresión de la conducta bajo un sustrato mental o espiritual. Tanto el psicoanálisis como el humanismo, incluso la teoría cognitivo conductual (en la versión de Ellis) ofrecen una imagen de la mente y sus dinámicas, estableciendo predicciones sobre su funcionamiento, lo cual implica una aplicación ordenada bajo el marco de control de variables, que deriva en técnicas diseñadas para alcanzar fines terapéuticos bajo el marco de ciencias de la mente. Es decir, se tiene un conocimiento sobre el funcionamiento del objeto, lo que hace posible la tematización de sus disfunciones y la proyección de un modelo correctivo que ayude a quitar los obstáculos que impiden su pleno funcionamiento o realización de su naturaleza constitutiva.

Para ampliar la discusión, habrá que analizar que la teoría humanista refiere la psique o yo bajo un teleologismo explícito, el de la autorealización entendida como recuperación de la coherencia

\footnotetext{
${ }^{13}$ Entendemos por crisis existenciales las que se presentan en distintos ciclos de la vida y se manifiestan en la necesidad de preguntarse y responderse por cuestiones de talante metafísico como el sentido de la vida, el fin de la misma, su origen, la razón del dolor, de la muerte, de la injusticia, del sufrimiento, la existencia de Dios. Definimos a las crisis cognoscitivas como momentos en donde las creencias o conocimientos previos no resultan suficientes a la exigencia de la razón y piden ser modificadas mediante procesos de análisis y crítica que buscan una imagen más racional y verás del mundo.
} 
entre un yo real y el yo imaginado. ¿Pero quién nos podría asegurar que este es el fin de la psique, cuando el psicoanálisis, por ejemplo, establece que el fin de la vida mental será el Nirvana o punto cero $^{14}$, es decir, el equilibrio adaptativo y económico de la pulsiones? Cuando se parte de estas imágenes de la mente o psique, se aplican metáforas de funcionamiento óptimo o deficiente de la mente, juzgando, a través de procesos diagnósticos, que existen conflictos o configuraciones sustanciales o relacionales que demandan atención terapéutica y que deben abordarse con estrategias o intervenciones intencionadas que han conocido los alcances tanto del problema como de la solución. Esto supone la afirmación y confianza sobre un modo particular de funcionamiento psíquico o espiritual, sin detenerse en los problemas conceptuales, metodológicos o filosóficos que se pueden plantear al respecto. Sabemos desde el ámbito filosófico que la mente, en cuanto su condición ontológica y teleológica, sigue representado un problema filosófico de gran envergadura, aumentado por el protagonismo actual de las neurociencias. El objeto de las psicoterapias será determinar el funcionamiento del objeto con el fin de trazar rutas de acción que derivarán en el modelaje de la acción de los sujetos bajo el riesgo de asumir una teleología y fines que podrían no responder a su condición ontológica más verdadera. La consultoría filosófica, liberada de las exigencias de la efectividad de la acción para la consecución de un determinado objetivo, podrá plantearse el objeto como una condición a determinar o asumir de manera más amplia, en más vertientes.

Sobre las diferencias entre ambos abordajes en este punto, podemos decir que la consultoría filosófica renuncia a la afirmación

${ }^{14}$ Freud sostiene esto en "Más allá del principio del placer", Obras completas, vol. XVIII, Amorrortu, Argentina, 1975, p. 38. 54-55., aunque modificará este juicio en "El problema económico del masoquismo", en Obras completas, vol. XIX, Amorrortu, Argentina, 1992, p. 166. 
exclusiva de un modelo particular de la mente o de la "psique", ya que su objeto no es la mente o la psique, sino la veracidad de los contenidos del pensamiento, el logos, la validez del worldview interpretation, la conciencia autónoma y la filosofía personal. El juicio del filósofo escapa pues, a una imagen de la mente como totalidad de lo real y su representación. Conceptos como razón, libertad, voluntad, trascendencia, indeterminación, imagen del mundo, entre otros pueden ser más abarcantes de la realidad humana y escapar a las determinaciones teóricas y técnicas de los conceptos determinados sobre la mente. Es decir, las imágenes que tenemos sobre la mente pudieran no ser la mente en su totalidad y, si lo fuesen, tampoco serían necesariamente integradores de todas las dimensiones humanas más reflexionadas por la filosofía: el asombro, la vida, la muerte, la libertad, la indeterminación, la dimensión metafísica de la vida y del conocimiento, la indagación, la capacidad de experimentar y preguntarse por el absoluto, la angustia, la utopía, la felicidad, el dolor, entre muchas. No porque dichas dimensiones se den fuera de la mente, sino porque tienen sus propias definiciones filosóficas que escapan al marco de las teorías dela mente. Tampoco afirmamos que en la psicoterapia no se pueda trabajar sobre estos tópicos, si no que cuando ello sucede se realiza teniendo como objeto a la psique y sus leyes o dinámicas, lo cual delimita la interpretación en los marcos de sentidos de esos modelos teóricos sobre la mente y establece una pauta a seguir para la consecución de ciertos fines. Agregaría a esto que las psicoterapias mencionadas, integran y trabajan con conceptos filosóficos que no necesariamente son evaluados y analizados como si sucede en el marco de la filosofía. Esto se comprende porque la función principal de los contenidos teóricos y estratégicos sobre el objeto de las psicoterapias, es dar respuesta a la situación temporal que apremia una acción. Esto pueda resultar en ignorar en qué momento una reflexión o acción sobre el objeto de la psicoterapia pueda tener un fondo filosófico pasando este momento inadvertido. 
En general, los modelos de mente de las corrientes psicológicas llevan implícita una teleología más o menos explícita: el desarrollo, realización y plenitud del organismo espiritual (humanismo), la homeostasis en el aparato psíquico (psicoanálisis ortodoxo), la desactivación del sufrimiento psíquico y adaptación de conductas (cognitivo conductual), el desarrollo de la condición espiritual (logoterapia), la superación o intervención en algún trastorno de la personalidad (psicología clínica), entre otros. ${ }^{15}$ En cambio, la consultoría filosófica se establece como una actividad sin fines definitivos o concluyentemente anclados en concepciones teleológicas exclusivas, ni en modelos psicopatológicos a superar. Es decir, el fin de la consultoría filosófica y el modo en que se entenderá su objeto podrá ser determinado en el propio proceso de consultoría; es más, puede discutirse si es posible establecerse un fin tanto para el proceso mismo de la consultoría como para la vida y si es posible determinar qué se entenderá por ese fin y cómo se validará que se ha arribado al mismo.

Diferencias entre consultoría filosófica y otros abordajes en cuanto al método

Otra particularidad de la consultoría filosófica en relación a las psicoterapias es la posibilidad de validar el método a utilizar. Se parte de la consideración siguiente: el consultante es un sujeto libre, único, racional con posibilidades de autodeterminación, inaprensible por las concepciones antropológicas con las que se cuente. Por ello, puede dialogarse con él, si lo sugiere o demanda,

\footnotetext{
${ }^{15}$ Somos conscientes que dentro de los modelos mencionados existen variedades de modelos, por ejemplo, en el psicoanálisis existe la escuela freudiana, la de las relaciones objetales, la de la psicología del yo, la escuela relacional, etc., y que mi caracterización puede ser muy reducida, sin embargo, en cuanto que las variantes teóricas se originan en modelos específicos de la mente seguirán postulando una teleología más o menos explícita.
} 
el método a desarrollar en el proceso de consultoría. Esto puede realizarse con un fin exploratorio: “¿qué métodos del pensar existen y qué relación guardan con el conocimiento humano y la tradición filosófica?", o con fines de validación: “¿cuál sería el mejor método para mi dadas las demandas particulares?"; incluso, una vez elegido el método, se puede preguntar: ¿es posible advertir deficiencias o alcances sobre el método y su idoneidad no sólo en relación con el proceso de la consultoría, sino para la filosofía en general?". En cambio, en los modelos psicológicos o psicoterapéuticos el método de abordaje no se convierte primariamente en un objeto de la reflexión, sino que se considera el camino para obtener los objetivos deseados. Tiene más el carácter de una técnica que de un elemento sobre el cual hay que pensar. En la consultoría filosófica dialogar sobre el método redunda directamente en la habilidad de hacer conciencia de sí en el consultante, al integrarlo activamente en la determinación del camino a seguir, sugiriendo con ello que en el terreno de la filosofía existen diversas posibilidades para tratar con uno mismo y la vida; en la psicoterapia, en cambio, dialogar sobre el método comporta un carácter informativo y, en ocasiones, no se abre a la consideración del consultante por valorar que no beneficia el proceso. Por ejemplo, en las terapias estratégicas se ofrecen sesiones guiadas por métodos paradójicos en donde se considera contraproducente explicar la razón de tal método de trabajo. En el abordaje filosófico no pudiera darse el caso de que algún elemento no deba cuestionarse o analizarse racionalmente, pues, como hemos dicho, el propio método de trabajo puede ser sujeto de análisis y nos puede dar pistas de las determinaciones filosóficas del consultante, así como abrirnos al cultivo y desarrollo de competencias filosóficas. 
Diferencias entre consultoría filosófica y otros abordajes en cuanto al papel del diálogo

Otro elemento particular de la consultoría filosófica se establece en la consideración del diálogo. Podemos decir que en su generalidad, la consultoría filosófica valora el diálogo no sólo como medio, sino como el elemento fundamental de toda labor filosófica. El diálogo es la condición de posibilidad de toda acción filosófica. El diálogo libre, autónomo y racional se distingue de las comunicaciones prescriptivas, de órdenes y afirmaciones definitivas sobre algún tópico de la vida como sucede en momentos y procesos dentro de la psicoterapia. Para ésta, el diálogo se convierte en el vehículo donde se desarrollan los elementos mencionados que se consideran en su constitución como terapéuticos. En cambio, el diálogo es objeto, medio y fin en la Consultoría Filosófica, funge como base para descubrir la verdad personal y comunitaria. Si bien, en las psicoterapias el diálogo es reflexionado en cuanto su ser terapéutico, adjudicándosele las notas mencionadas, representa más bien un medio para desarrollar contacto afectivo profundo, órdenes, límites, comunicación cognoscitiva de interacciones inconscientes con el fin de la reestructuración afectiva y cognoscitiva que, como vimos, está determinada por el modo en que se concibe el objeto de la actividad.

Diferencias entre consultoría filosófica y otros abordajes en cuanto a la elección de un modo determinado de vivir.

Por otra parte y en marcada distinción con las psicoterapias psicodinámicas, de las que excluiría en este lugar a la logoterapia y al humanismo personalista, la consultoría filosófica puede incidir en la elección de un modo de vivir consciente que trasciende a la atención particular de algún problema, conflicto o dificultad de la vida cotidiana. Algunas corrientes de consultoría filosófica 
descansan en la idea de que la filosofía representa no sólo un cuerpo de conocimientos más o menos racionales o ciertos, sino que se identifica con la totalidad de la intención de los actos de una vida. Nos referimos al cultivo y atención la vida lograda o la vida humanizada, que se activa sobre una búsqueda incesante de la verdad y la sabiduría, en un movimiento de desinstalación constante y abierto; referimos a lo que definimos en el cuarto aspecto del objeto sobre el que va la consultoría filosófica según este artículo. Estamos afirmando pues que la consultoría filosófica puede incitar a la realización de una vida filosófica, en donde los resultados del pensar deben afectar la coherencia de la estructura de la existencia personal y no sólo la atención temporal a algún problema, dificultad o dimensión de la psique. En cambio, los abordajes psicoterapéuticos buscan incidir sobre algún asunto particular de las dimensiones vitales de una persona (afectos, relaciones familiares o de pareja, pretensiones mejores sobre lo económico o lo laboral, etc.) y en un tiempo determinado de su ciclo de vida, pudiendo dejar de lado sin problematización alguna una pretensión ética de vida buena o vida feliz en sentido filosófico.

Diferencias entre consultoría filosófica y otros abordajes en cuanto a la consideración del consultante/cliente/paciente

Por último, añado una peculiaridad y diferencia en torno al concepto que se tiene sobre el consultante/cliente/paciente. La concepción que desde la consultoría filosófica se tiene del consultante es variada, pero en general se considera como un igual bajo una explícita afirmación de simetría en la relación consultanteconsultado. Por ejemplo, Achenbach llamará a su interlocutor huésped, Cavallé lo nombra consultante y Marinoff lo llama cliente. Se estima que el consultor filosófico tiene frente a sí un sujeto libre, autónomo, responsable de sí, no enfermo ni etiquetado 
por alguna denominación psicológica o psiquiátrica. La relación interpersonal se considera simétrica y centra el proceso en el desarrollo de las capacidades reflexivas y argumentales del consultante. Al consultante se le ve como un par, aunque demande la relación de acompañamiento. Esto no elimina el rol del filósofo consultante como un maestro o como un guía en el discurrir filosófico. El consultor filosófico no define la tarea en su expertise, pues, en última instancia, el consultante tiene ante sí una tarea personal que se ve acompañada filosóficamente, en donde los elementos que se aceptan no se ven movidos, empujados o configurados por una relación asimétrica, sino por la autonomía y voluntad en la reflexión personal del consultante. Los abordajes psicoterapéuticos en cambio, (aunque podemos excluir de este juicio al humanismo rogeriano) especialmente cuando no se implica un padecimiento mental, promueven un carácter asimétrico donde el terapeuta juega un rol que lo distingue de los otros por su expertise en el manejo de las técnicas y teorías de la psicología aplicada, y que incluso puede utilizar dicha asimetría con fines terapéuticos (la prohibición de consumos de sustancias nocivas para la salud en las adicciones, la determinación de medicación como una prescripción necesaria para seguir el tratamiento o la prohibición de aislamiento social en un depresivo con intentos suicidas). No tenemos ningún juicio peyorativo sobre la asimetría en la relación terapéutica mientras que ésta se utilice rigurosamente con fines terapéuticos. Aunque cabe señalar que bajo una mirada contemporánea en donde el papel y rol de autoridad son ampliamente cuestionados, se han observado nuevas reflexiones y cambios en la concepción del papel jerárquico entre el consultante/cliente/paciente y el profesional acompañante cuestionando el punto de partida desde un supuesto saber exclusivo y excluyente de la persona en el tratamiento de su propio proceso, evitando la tutela por parte del experto. 


\section{¿Qué comparten en lo esencial la consultoría filosófica y los abordajes psicoterapéuticos?}

Comenta Peter B. Raabe: "One of the primary goals in philosophical counseling is for the client to be self reflective. In dialogue the philosophical counselor invites his client to turn her inner thinking to an intersubejtive exchange that have the potencial to result in better self-understanding." $"$ Tanto los abordajes filosóficos como los psicoterapéuticos pueden fomentar el desarrollo del propio pensamiento (autonomía en el pensar desde la consultoría filosófica o pensar como un self o como una mente equilibrada desde las psicoterapias). Ambos abordajes ponen en movimiento a la subjetividad para establecerse más objetiva, menos autorreferenciada, más en el nosotros y menos en el sí mismo. Persiguen romper la estreches de representaciones de sí y de la realidad (la realidad en totalidad en la consultoría filosófica o la realidad personal o realidad de la psique en la psicoterapia), así como derivar en el bienestar de las relaciones interpersonales, sea esto último y central o periférico (para la consultoría filosófica esto podría ser una derivación del proceso más no su centro mientras que para la psicoterapia pudiera convertirse en un objetivo central del proceso).

Como hemos mostrado, los objetos y la consideración que cada abordaje pueden coincidir en los efectos, aunque el modo de establecer dichos objetos, como vemos, es muy distinto. En otras palabras, un consultor filosófico no realiza psicoterapia, aunque pueda con su servicio incidir en dimensiones que se consideran objeto de la psicoterapia tales como el comportamiento, la autorepresentación y miradas más conscientes y reflexivas sobre las relaciones interpersonales. Así mismo puedo decir que es más

${ }^{16}$ RAABE, Peter B.; Philosophical counseling: theory and practice, Praeger, Connecticut, 2001, p. 205. 
probable que el psicoterapeuta haga filosofía por momentos o espacios, pues se encuentra frecuentemente con situaciones donde el tratamiento y las técnicas aplicadas a la rehabilitación mental se encuentren superadas, pues ya no tratan solo del sufrimiento de la mente, sino de concepciones de vida filosóficas, así como la aparición de preguntas radicales sobre el sentido del sufrimiento o del sentido del lugar en el mundo del acompañante, lo cual implica situaciones inesperadas que exigen al profesional ir más allá de lo dado e indagar sobre concepciones de la vida alternativas y posibilitantes no solo del espacio terapéutico, sino también fuera de él.

¿Qué lugares comunes pueden compartir ambos abordajes?

Creo que esto puede lograrse en la valoración de la historia de la filosofía. Todas las personas que demandan un acompañamiento ante cuestiones de la vida cotidiana lo realizan a través de conceptos con los que buscan englobar qué es lo que les sucede. Esto se traduce en preguntas concretas como ¿qué es el amor? ¿Qué es una relación de pareja? ¿Qué sentido tiene la vida ante la dificultad? ¿Existen valores universales que me puedan orientar o debo yo elegirlos y construirlos de modo personal? ¿Es la vida una carga o una bendición? ¿Para qué tener hijos? ¿Qué son los hijos? ¿Qué es vivir? ¿Qué es ser feliz? ¿Qué es el fracaso? ¿Cómo afronto la conciencia de la muerte?, ¿Para qué vivir responsablemente a pesar de la no recompensa inmediata? ¿Para qué amar eróticamente a una persona si lo puedo hacer con más? ¿Para qué crecer mentalmente si puedo recibir ganancias personales de mi estado actual?, por comentar algunos ejemplos. La historia de la filosofía puede analogarse con un baúl repleto de joyas por descubrir que pueden iluminar la vida y transformar el modo en que valoramos las cosas. Son los filósofos quienes han tenido el coraje, el acierto, la dedicación y en algunos casos la intrepidez de reflexionar sobre los tópicos más desconcertantes con radicalidad y pretensión de fundamentación. 
Además, como menciona Marinoff ${ }^{17}$ existen demandas filosóficas en las personas y éstas no serán satisfechas por abordajes no filosóficos. Es decir, existen problemas netamente filosóficos, aquellos referidos a la búsqueda de sentido último, a la sensación de vacío existencial, a la pretensión de una mayor racionalidad de los elementos del mundo y las acciones, y aquellos que surgen naturalmente en todo ser humano que se da la oportunidad de asombrarse y extrañarse con la complejidad, problematicidad y riqueza de la vida. No existe psicoterapia que pueda satisfacer la desazón de estos motivos del pensar, esto siempre ha sido terreno de la filosofía.

Por tanto, afirmamos que el lugar común entre los abordajes es la experiencia humana en su búsqueda de ultimidad y fundamentación de las acciones y el vivir con sentido. Todo aquel que busque eliminar el sufrimiento mental de manera inmediata a través de la psicoterapia se puede beneficiar del modo en que la filosofía enmarca las cosas en el horizonte reflexivo, amplio y crítico. Y toda labor filosófica puede comenzar en la demanda personal y existencial de consolar y reconciliarnos con el dolor que puede producir la vida o sus diversas situaciones.

¿Es la consultoría filosófica aplicable en todos los casos?

Del mismo modo, queremos resaltar que la consultoría filosófica no es aplicable universalmente a todo proceso y en todo momento si se tiene como criterio de implementación el bienestar personal y social. Es claro que esto es discutible en la consulta filosófica y que, de hecho, pudiese ser un asunto a tratar como objetivo. Pero avanzando sobre esta aporía, se pudiera dar el caso de que la consulta filosófica pudiera servir como sucedáneo o evasiva de un proceso más adecuado para determinadas personas bajo dificultades específicas. La imagen del consultante/cliente/huésped

${ }^{17}$ MARINOFF Lou, Philosophical practice. Academic Press, USA, 2001, págs. 169-171. 
filosófico no siempre se da en lo real y pueden existir fallas en funciones emocionales y cognoscitivas básicas que pueden ser ignoradas por los consultores filosóficos. Por ejemplo, ¿qué sucede ante la evasiva, tanto del consultante como del consultor, de integrar las emociones tomando como refugio a la razón? ¿Debo llegar hasta las últimas consecuencias de reflexionar críticamente sobre el suicidio ante una persona en depresión grave, sabiendo del condicionamiento temporal de su cerebro? En otras palabras, una consultoría filosófica pudiera incidir en fomentar o ignorar una dificultad afectiva-mental importante cuando algún consultante envuelto en la dinámica de priorizar los procesos racionales y lógicos, haga distancia de dinámicas físicas y mentales reales que le aquejan y apremian. Ante un sujeto abismado de emociones o escindido de ellas, los procesos de reflexión filosófica pudieran servir como máscaras que dificulten la autenticidad y autonomía de la persona, fragmentando su integración como ser vital a la totalidad de la vida.

Nuestra experiencia en ambos campos nos permite establecer que la indicación de un problema mental mayor no excluye por sí misma ala filosofía; es más, destacamos la afirmación de Frankl acerca de que la psique puede enfermar, mas no el espíritu o la conciencia. ${ }^{18}$ Aún en situaciones de enfermedad mental la conciencia de la persona puede guardar una básica lucidez y la persona se puede beneficiar ampliamente de la consultoría filosófica. Existen algunos trastornos psicóticos, de ansiedad y condiciones como el asperger (dependiendo del segmento de su espectro) donde pudiera establecerse una buena relación a través de conversaciones filosóficas como vehículo importante de integración de los sujetos, estableciendo lazos que difícilmente podrían lograrse mediante un vínculo que tuviera como objeto la relación emocional y la amenaza de intimidad afectiva. Por

${ }^{18}$ FRANKL, Víctor, Psicoanálisis y existencialismo, FCE, México, 1978, p. 43 
ejemplo, el trabajo sobre conceptos abiertos como vida, muerte, amor, sentido suelen ser temas del diálogo de personas con trastornos de ansiedad moderados o graves que bien pudieran derivarse en procesos de consultoría filosófica. Algunas psicosis funcionales donde los sujetos cuestionan constantemente el sentido de su enfermedad y conceptos básicos como muerte y vida, podrían ser abordadas mediante la labor reflexiva de la filosofía. No obstante, debemos tener cuidado en la clasificación que se menciona aquí, pues solo representa una experiencia de trabajo. Sin duda existe la necesidad de generar investigaciones al respecto. Es importante considerar lo anterior, pues el elenco de enfermedades, trastornos y dificultades mentales son diversas y no sobre todas se podrían generar las recomendaciones anteriores.

Espero que este texto haya servido como un esbozo para determinar lo propio de la consulta filosófica y lo distinto de la misma en relación con los abordajes psicoterapéuticos. La línea suele ser muy delgada y lo importante, más que su distinción teórica y práctica, será la conciencia de saber cuándo recurrir a cada abordaje según las necesidades, motivaciones y fines de cada consultante. Lo que nos interesa y esperamos haber sugerido, más allá de las distinciones elaboradas, es como mostrar la vigorosa y vigente utilidad de la filosofía que, sin pretensiones clínicas, puede intervenir sobre los problemas más acuciantes de la vida personal y comunitaria con las características que históricamente la han definido, sin psicologizar o medicalizar sus pretensiones.

\section{Bibliografía}

Arnáiz, Gabriel “¿Qué es la filosofía práctica?”, en A parte Rei 53, septiembre 2007 
Barrientos Rastrojo, José, Dominios de Aplicación Práctica de la filosofía, Ediciones X-XI, Sevilla, 2006. (En línea) Disponible en: http://www.asepraf.org.bibliografia/

Bleichmann, Lieberman, El psicoanálisis después de Freud, Paidós, Barcelona, 1997.

Brenifier, Oscar, “¿Puede la fillosofía convertirse en una práctica?”, Diálogo Filosófico, 68, 2007.

Filosofar como Sócrates, Diálogo, Madrid, 2011

Brenifier, Oscar - Millon, Isabelle, "Cuaderno 1 de ejercicios de práctica filosófica en la escuela", Cecapfin, México DF.

Canalez Valenzuela, Iván, "Filosofía desde el horizonte de la praxis", (Chile: Universidad católica del Maule), en http://www.postgrado

unesr.edu.ve/acontece/es/todosnumeros/num11/01_04/filosofiadesde-el-horizonte-de-la-praxis1.pdf (consultado el 25 de octubre de 2016)

Cavallé, Mónica, La sabiduría recobrada. Filosofía como terapia, Kairós, Madrid, 2002.

La filosofía, maestra de vida, Grupo Santillana Aguilar, Madrid, 2004

$\mathrm{El}$ asesoramiento filosófico: una alternativa a las psicoterapias, consultado

https://piensathelos.files.wordpress.com/2012/09/cavallc3a9-cruzmc3b3nica-el-asesoramiento-filosc3b3fico-una-alternativa-a-laspsicoterapias.pdf (consultado el 10 de agosto de 2016).

Hadot, Pierre, ¿Qué es la filosofía antigua?, FCE, México, 1998

Ejercicios espirituales y filosofía antigua, Siruela, España, 2006

UNESCO, La filosofía, una escuela para la libertad, UNESCOUAM, México, 2007

Kreimer, Roxana, Artes del buen vivir, Paidós, Barcelona, 2005 
Nussbaum, Martha, La terapia del deseo, Paidós, Barcelona, 2003. Marinoff, Lou. Philosophical practice. Academic Press, USA, 2001

Raabe, Peter, Philosophical counseling, Praeger, USA, 2001

Selvini - Palazolli et Al, "Hypothesizin, Circularity, Neutrality: Three Guidelines for the Conductor of the Session", Family Process, 193 - 12. 1980

Valencia, Oscar, El psicoanálisis en la posmodernidad como contracultura,

en https://www.academia.edu/4278704/El_psicoan\%C3\%A1lisis_en_1 a_posmodernidad_como_contracultura, (consultado el 1 de octubre de 2018). 
